\title{
Intravoxel Incoherent Motion MR Imaging of Pediatric Intracranial Tumors: Correlation with Histology and Diagnostic Utility
}

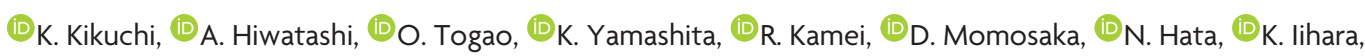
(1) S.O. Suzuki, $\mathbb{1}^{\mathrm{T}}$. Iwaki, and $\mathbb{D}^{-} \mathrm{H}$. Honda

\begin{abstract}
BACKGROUND AND PURPOSE: Intravoxel incoherent motion imaging, which simultaneously measures diffusion and perfusion parameters, is promising for brain tumor grading. However, intravoxel incoherent motion imaging has not been tested in children. The purpose of this study was to evaluate the correlation between intravoxel incoherent motion parameters and histology to assess the accuracy of intravoxel incoherent motion imaging for pediatric intracranial tumor grading.
\end{abstract}

MATERIALS AND METHODS: Between April 2013 and September 2015, 17 children (11 boys, 6 girls; 2 months to 15 years of age) with intracranial tumors were included in this retrospective study. Intravoxel incoherent motion parameters were fitted using 13 b-values for a biexponential model. The perfusion-free diffusion coefficient, pseudodiffusion coefficient, and perfusion fraction were measured in highand low-grade tumors. These intravoxel incoherent motion parameters and the ADC were compared using the unpaired $t$ test. The correlations between the intravoxel incoherent motion parameters and microvessel density or the MIB-1 index were analyzed using the Spearman correlation test. Receiver operating characteristic analysis was used to evaluate diagnostic performance.

RESULTS: The perfusion-free diffusion coefficient and ADC were lower in high-grade than in low-grade tumors (perfusion-free diffusion coefficient, $0.85 \pm 0.40$ versus $1.53 \pm 0.21 \times 10^{-3} \mathrm{~mm}^{2} / \mathrm{s}, P<.001 ; A D C, 1.04 \pm 0.33$ versus $\left.1.60 \pm 0.21 \times 10^{-3} \mathrm{~mm}^{2} / \mathrm{s}, P<.001\right)$. The pseudodiffusion coefficient showed no difference between the groups. The perfusion fraction was higher in high-grade than in low-grade tumors ( $21.7 \pm 8.2 \%$ versus $7.6 \pm 4.3 \%, P<.001)$. Receiver operating characteristic analysis found that the combined perfusion-free diffusion coefficient and perfusion fraction had the best diagnostic performance for tumor differentiation (area under the curve $=0.986$ ).

CONCLUSIONS: Intravoxel incoherent motion imaging reflects tumor histology and may be a helpful, noninvasive method for pediatric intracranial tumor grading.

ABBREVIATIONS: $D=$ perfusion-free diffusion coefficient; $D^{*}=$ pseudodiffusion coefficient; $f=$ perfusion fraction; $I$ VIM = intravoxel incoherent motion; $M V D=$ microvessel density; $\mathrm{ROC}=$ receiver operating characteristic; $\mathrm{WHO}=$ World Health Organization

B rain tumors are the second most common tumors in the pediatric population. ${ }^{1}$ Each year, approximately 2500 children are diagnosed with brain tumors in the United States. ${ }^{2}$

Received December 19, 2018; accepted after revision March 27, 2019.

From the Departments of Clinical Radiology (K.K., A.H., O.T., K.Y., R.K., D.M., H.H.), Neurosurgery (N.H., K.I.), and Neuropathology (S.O.S., T.I.), Graduate School of Medical Sciences, Kyushu University, Fukuoka, Japan.

This work was supported by JSPS KAKWNHI Grant Number $18 \mathrm{H} 06164$

Paper previously presented, in part, at: Scientific Assembly and Annual Meeting of Radiological Society of North America, November 29 to December 4, 2015; Chicago, Illinois: No. VSPD11-03.

Please address correspondence to Akio Hiwatashi, MD, PhD, Department of Clinical Radiology, Graduate School of Medical Sciences, Kyushu University,

3-1-one Maidashi, Higashi-ku, Fukuoka 812-8582, Japan; e-mail:

hiwatasi@radiol.med.kyushu-u.ac.jp

-- Indicates open access to non-subscribers at www.ajnr.org

$\square$ Indicates article with supplemental on-line photos.

http://dx.doi.org/10.3174/ajnr.A6052
Pediatric brain tumors are different from those of adults, with specific infantile subtypes and pathologic features that are widely heterogeneous. ${ }^{1}$ Accurate preoperative diagnosis is beneficial for determining the appropriate therapeutic strategy; however, this remains challenging because of tumor variability and heterogeneity.

MR imaging plays an important role in the accurate diagnosis of brain tumors. Many attempts have been made to identify biomarkers on $\mathrm{DWI}^{3,4}$ and $\mathrm{PWI}^{5,6}$ that can be used to grade pediatric brain tumors and those found in adults. ${ }^{7,8}$ In clinical practice, the ADC is usually calculated using $2 \mathrm{~b}$-values ( 0 and $1000 \mathrm{~s} / \mathrm{mm}^{2}$ ) and serves as a useful biomarker, reflecting cellular density. ${ }^{4,9}$ Similar to the ADC, $\mathrm{CBV}$ and CBF are also useful biomarkers. ${ }^{5,6,10}$ Measuring DSC-derived CBV requires an intravenous gadolinium-based contrast agent. Thus, this method can be difficult to implement in children. ${ }^{5}$ DSC imaging often requires high-flow contrast injection by power injectors requiring large-bore intravenous access, which presents chal- 


\begin{tabular}{|c|c|c|c|c|c|c|c|c|c|}
\hline \multirow[b]{2}{*}{ No. } & \multirow[b]{2}{*}{ Age, Sex } & \multicolumn{4}{|l|}{ Histology } & \multicolumn{3}{|c|}{ IVIM Parameters } & \multirow[b]{2}{*}{$\begin{array}{c}\mathrm{ADC} \\
\left(\times 10^{-3} \mathrm{~mm}^{2} / \mathrm{s}\right)\end{array}$} \\
\hline & & Pathologic Diagnosis & $\begin{array}{l}\text { WHO } \\
\text { Grade }\end{array}$ & $\begin{array}{c}\text { MIB-1 } \\
(\%)\end{array}$ & MVD & $\mathrm{D}\left(\times 10^{-3} \mathrm{~mm}^{2} / \mathrm{s}\right)$ & $f(\%)$ & $D^{*}\left(\times 10^{-3} \mathrm{~mm}^{2} / \mathrm{s}\right)$ & \\
\hline 1 & $6 \mathrm{yr}, \mathrm{M}$ & Diffuse midline glioma, $\mathrm{H} 3 \mathrm{~K} 27 \mathrm{M}$-mutant & IV & 59.2 & 3.1 & 1.50 & 16.4 & 5.6 & 1.61 \\
\hline 2 & $4 \mathrm{yr}, \mathrm{M}$ & Medulloblastoma, classic, histologically defined & IV & 15.6 & 34.7 & 0.30 & 37.7 & 13.7 & 0.56 \\
\hline 3 & $11 \mathrm{yr}, \mathrm{M}$ & Medulloblastoma, classic, histologically defined & IV & 72.6 & 10.2 & 0.53 & 27.1 & 30.2 & 0.87 \\
\hline 4 & $3 y r, M$ & Atypical teratoid/rhabdoid tumor & IV & 50.0 & 11.0 & 0.86 & 14.1 & 9.0 & 0.98 \\
\hline 5 & $2 \mathrm{yr}, \mathrm{F}$ & Anaplastic ependymoma & III & 23.2 & 12.5 & 0.87 & 19.3 & 18.4 & 1.02 \\
\hline 6 & $3 y r, M$ & Anaplastic ependymoma & III & 19.6 & 4.3 & 1.15 & 16.8 & 5.5 & 1.30 \\
\hline 7 & $6 \mathrm{yr}, \mathrm{F}$ & Anaplastic ependymoma & III & 58.4 & 10.1 & 0.71 & 20.7 & 41.7 & 0.96 \\
\hline 8 & $12 \mathrm{yr}, \mathrm{M}$ & Diffuse astrocytoma, IDH wild-type & II & 2.1 & 2.1 & 1.22 & 8.4 & 33.3 & 1.29 \\
\hline 9 & $1 \mathrm{yr}, \mathrm{M}$ & Pilocytic astrocytoma & 1 & 4.4 & 5.8 & 1.45 & 3.5 & 5.5 & 1.50 \\
\hline 10 & $3 \mathrm{yr}, \mathrm{F}$ & Pilocytic astrocytoma & 1 & 6.7 & 4.0 & 1.82 & 7.2 & 10.2 & 1.88 \\
\hline 11 & $3 y r, M$ & Pilocytic astrocytoma & 1 & 8.0 & 4.7 & 1.52 & 10.0 & 48.3 & 1.64 \\
\hline 12 & $6 y r, M$ & Pilocytic astrocytoma & 1 & 6.0 & 3.2 & 1.72 & 4.2 & 58.4 & 1.78 \\
\hline 13 & $11 \mathrm{yr}, \mathrm{F}$ & Pilocytic astrocytoma & 1 & 4.0 & 5.6 & 1.55 & 5.5 & 12.8 & 1.61 \\
\hline 14 & $2 \mathrm{yr}, \mathrm{M}$ & Subependymoma & 1 & 0.1 & 1.9 & 1.58 & 5.1 & 11.3 & 1.60 \\
\hline 15 & $2 \mathrm{mo}, \mathrm{F}$ & Choroid plexus papilloma & 1 & 0.1 & 13.4 & 1.47 & 17.4 & 11.6 & 1.62 \\
\hline 16 & $10 \mathrm{yr}, \mathrm{M}$ & Dysembryoplastic neuroepithelial tumor & 1 & 2.7 & 1.3 & 1.76 & 10.9 & 4.3 & 1.82 \\
\hline 17 & $15 \mathrm{yr}, \mathrm{F}$ & Ganglioglioma & 1 & 1.0 & 1.1 & 1.21 & 3.6 & 22.4 & 1.24 \\
\hline
\end{tabular}

Note:-IDH indicates isocitrate dehydrogenase.

lenges in young children and infants. ${ }^{5}$ In contrast, measuring CBF with arterial spin-labeling does not require a contrast agent; this feature is beneficial for children. ${ }^{5,6}$

In 1988, Le Bihan et $\mathrm{al}^{11}$ reported on an imaging technique depicting the molecular motion of water in tissue and used for distinguishing diffusion and perfusion components on the basis of the intravoxel incoherent motion (IVIM) model. The ADC contaminates contributions from capillary microcirculation because it cannot inherently separate the coherent motion of microperfusion with small b-values. ${ }^{11}$ Therefore, the ADC is influenced by perfusion and could be overestimated, especially in hypervascular tumors. IVIM imaging fits the signal decay to a biexponential function using multiple b-values and then discriminates perfusion-free diffusion from capillary perfusion, allowing the simultaneous evaluation of diffusion and perfusion parameters. Furthermore, the perfusion-free diffusion coefficient (D) can reveal the state of diffusion more accurately than the ADC because it is based on a model that does not rely on the influence of perfusion. IVIM imaging has been used to evaluate malignant tumors in adults (eg, glioma or head, neck, rectal, or breast cancers), ${ }^{12-15}$ and the IVIM perfusion parameter correlates with tumor histology in animals. ${ }^{16,17}$ However, to date, few studies have evaluated IVIM imaging in children. The purpose of this study was to evaluate the correlation between IVIM parameters and histology to assess the accuracy of IVIM imaging for pediatric intracranial tumor grading.

\section{MATERIALS AND METHODS}

This retrospective study was approved by our institutional review board, and the informed consent requirement was waived.

\section{Patients}

The inclusion criteria for this study are outlined in On-line Fig 1. Twenty-one consecutive pediatric patients with intracranial tumors who underwent IVIM imaging examinations between April 2013 and September 2015 were identified. On the basis of the exclusion criteria (On-line Fig 1), 1 patient with an inadequate histologic specimen and 3 patients with non-neuroectodermal tumors were excluded. Therefore, data from 17 patients ( 11 boys,
6 girls; median age, 4 years; range, 2 months to 15 years) with 7 high-grade (World Health Organization [WHO] grades III and IV; 5 boys, 2 girls; median age, 4 years; range, $2-11$ years) and 10 low-grade (WHO grades I and II; 6 boys, 4 girls; median age, 4.5 years; range, 2 months to 15 years) tumors were available for analysis.

\section{Histopathologic Diagnosis}

Patient demographics and pathologic diagnoses based on the 2016 WHO classification ${ }^{18}$ are shown in Table 1.

\section{IVIM MR Imaging}

IVIM imaging was performed as previously described ${ }^{12,19}$ using a 3T MR imaging scanner (Achieva 3T TX; Philips Healthcare, Best, the Netherlands) with an 8-channel head coil. The IVIM scans were obtained in the axial plane using a $2 \mathrm{D}$ single-shot spin-echo EPI diffusion sequence. We used $13 \mathrm{~b}$-values $(0,10,20,30,50,80$, $100,200,300,400,600,800$, and $1000 \mathrm{~s} / \mathrm{mm}^{2}$ ) in 3 orthogonal directions. The other IVIM imaging parameters were as follows: TR/TE, 2500/82 ms; matrix, $128 \times 126$ (reconstructed to $256 \times$ 256); NEX, 1; section thickness/gap, $5 / 1 \mathrm{~mm}$; FOV, $230 \times 230$ $\mathrm{mm}$; number of sections, 11 ; sensitivity encoding factor, 1.5 ; and total scan time, 2 minutes 10 seconds. IVIM imaging was acquired before contrast agent injection. Several standard MR images (T1WI, T2WI, FLAIR, and contrast-enhanced T1WI) were also obtained for diagnostic purposes.

\section{Image Analysis}

The IVIM parameters from each map with $13 \mathrm{~b}$-values were generated using a commercially available workstation (SYNAPSE VINCENT; Fujifilm Medical, Tokyo, Japan). ${ }^{20}$ For IVIM data analysis, the biexponential model was defined by the following equation:

1) $\frac{S I_{\mathrm{b}}}{S I_{0}}=f \times \exp \left(-b \times D^{\star}\right)+(1-f) \times \exp (-b \times D)$,

where $S I_{0}$ corresponds to the signal intensity without diffusion weighting $\left(b=0 \mathrm{~s} / \mathrm{mm}^{2}\right)$ and $S I_{\mathrm{b}}$ is the $S I$ acquired with different $\mathrm{b}$-values. First, the $D$ was determined from data with higher b-values $\left(b=300,400,600,800\right.$, and $\left.1000 \mathrm{~s} / \mathrm{mm}^{2}\right)$. When high b-val- 
ues were used and the IVIM component was negligible, we used the following least-squares curve fit:

$$
\frac{S I_{\mathrm{b}}}{S I_{0}}=\exp (-b \times D) .
$$

Second, the segmented method was used to calculate perfusion fraction $(f)$ according to the following equation:

3)

$$
f=\left(S I_{0}-S I_{\text {inter }}\right) / S I_{0} .
$$

Here, $S I_{\text {inter }}$ is the intersection point of the y-axis and a line through $\log _{\mathrm{e}} S I_{300}$ and $\log _{\mathrm{e}} S I_{1000}$. Third, the pseudodiffusion coefficient $\left(D^{*}\right)$ was derived from the monoexponential fit to Equation (1). The ADC was also calculated with b-values of 0 and 1000 $\mathrm{s} / \mathrm{mm}^{2}$ using the following equation:

$$
\frac{S I_{1000}}{S I_{0}}=\exp (-b \times A D C)
$$

Two board-certified neuroradiologists (K.K. and D.M., with 13 and 7 years of experience, respectively) evaluated each tumor using nonoverlapping ROIs (area, $>10 \mathrm{~mm}^{2}$ ). Three or more circular ROIs were placed on each tumor map. When placing the ROIs, we carefully avoided areas containing necrosis, hemorrhage, calcification, or blood vessels by referring to other sequences. The average ROI values were used as representative values for each parameter. D-map ROIs were copied to the corresponding ADC maps for comparison. Similarly, f-map ROIs were copied to the corresponding $\mathrm{D}^{*}$ maps.

\section{Histopathologic Evaluation}

Histologic microvessel density (MVD) was evaluated as previously described. ${ }^{6}$ Briefly, tissue sections were immunostained with anti-CD31 (Dako Japan, Tokyo, Japan). Stained vessels were viewed under a microscope using a $\times 20$ objective field. The MVD was calculated using the following equation:

MVD $=($ Anti-CD31 Immunostained Vascular Area $)$

$\div($ Total Tissue Area $)$

Three different fields were evaluated, and a mean representative value was calculated.

MIB- 1 is a monoclonal antibody to the Ki-67 antigen, which is expressed in proliferating and dividing cells during all active phases of the cell cycle (ie, $G_{1}, S, G_{2}$, and $M$ phases), but not during the $\mathrm{G}_{0}$ phase. ${ }^{21}$ The MIB-1 index is a marker of cell proliferation. ${ }^{22}$ All specimens were evaluated by the Department of Neuropathology using this index.

\section{Statistical Analysis}

We assessed the distribution of the data using the Shapiro-Wilk test. Each IVIM parameter (ie, D, $D^{*}$, and f) and the ADC, MVD, and MIB-1 index were compared between high- and low-grade tumors using the unpaired $t$ test. The $\mathrm{D}$ and $\mathrm{ADC}$ values were also compared within the high- and low-grade tumor groups by a paired $t$ test. The Mann-Whitney $U$ test was used when these data deviated from a normal distribution.

The relationships between the MIB-1 proliferation index and diffusion parameters (ie, D and ADC) were evaluated by the Pearson correlation test, and those between the MVD and IVIM perfusion parameters (ie, $\mathrm{D}^{*}$ and $\mathrm{f}$ ) were evaluated by the Spearman correlation test.

The diagnostic performances of each IVIM parameter and the ADC were evaluated by receiver operating characteristic (ROC) curve analysis.

All the statistical analyses were performed using commercial software programs (JMP, Version 11.0.0; SAS Institute, Cary, North Carolina; GraphPad Prism 7.0, GraphPad Software, San Diego, California; MedCalc for Windows, Version 15.10.0, MedCalc Software, Mariakerke, Belgium). A $P$ value $<.05$ was considered statistically significant.

\section{RESULTS}

\section{Differentiation of High- and Low-Grade Tumors Using IVIM Parameters}

Figure 1 and Table 2 summarize the parameter measurements for pediatric intracranial neuroectodermal tumor grading. The $\mathrm{D}$ and ADC were lower in high-grade than in low-grade tumors (D, $0.85 \pm 0.40$ versus $1.53 \pm 0.21 \times 10^{-3} \mathrm{~mm}^{2} / \mathrm{s}, P=.0003$; ADC, $1.04 \pm 0.33$ versus $1.60 \pm 0.21 \times 10^{-3} \mathrm{~mm}^{2} / \mathrm{s}, P=.0007$; Fig $1 A$ and Table 2). The $\mathrm{D}^{\star}$ showed wide variability and no significant differences between tumor grades $(P=.8337$; Fig $1 B$ and Table 2$)$. The $\mathrm{f}$ was higher in high-grade than in low-grade tumors $(21.7 \pm$ $8.2 \%$ versus $7.6 \pm 4.3 \%, P=.0003$; Fig $1 C$ and Table 2 ).

\section{Comparison of the D and ADC Values}

The $\mathrm{D}$ was significantly lower than the ADC in high- $(P=.0010)$ and low-grade $(P=.0004$; Fig $1 A)$ tumors. The percentage difference between the $\mathrm{D}$ and $\mathrm{ADC}$ was $23.3 \% \pm 22.0 \%$ in the highgrade tumors and $4.4 \% \pm 18.9 \%$ in the low-grade tumors.

\section{Relationship between the IVIM Parameters and MVD}

On-line Figure 2 shows the relationship between each IVIM parameter and histology. There were strongly negative correlations between the MIB-1 proliferation index and $\mathrm{D}(r=-0.577, P=.0154$; Online Fig 2A) and $\operatorname{ADC}(r=-0.517, P=.0334$; On-line Fig $2 B)$. Notably, the correlation value of the $\mathrm{D}$ was higher than that of the ADC ( -0.577 versus -0.517 ; On-line Fig $2 A,-B)$. There was a strongly positive correlation between the fand $\operatorname{MVD}(\rho=0.832, P<$ .0001; On-line 1 Fig $2 D$ ). There was no significant correlation between the $\mathrm{D}^{\star}$ and $\operatorname{MVD}(\rho=-0.088, P=.7380$; On-line Fig $2 C)$.

\section{ROC Analysis of Each IVIM Parameter for Grading Pediatric Intracranial Tumors}

Table 3 and On-line Fig 3 show the ROC analysis results for the diagnostic performance of each IVIM parameter in differentiating high- and low-grade tumors. The combined D and $f$ showed the best diagnostic performance (area under the curve $=0.986$ ). The $\mathrm{D}, \mathrm{ADC}$, and $\mathrm{f}$ also showed robust diagnostic performance (area under the curve $=0.943,0.907$, and 0.957 , respectively). The $\mathrm{D}^{\star}$ showed low diagnostic performance (area under the curve $=$ 0.536). The optimal diagnosis cutoff values for discriminating high- and low-grade tumors were $\leq 1.50$ and $>16.4$ for the combined $\mathrm{D}$ and f, respectively ( $\leq 1.15$ for the $\mathrm{D}, \leq 1.02$ for the ADC, and $>14.1$ for the $\mathrm{f}$ ).

Figures 2 and 3 show representative patients with grades IV (medulloblastoma) and I (pilocytic astrocytoma) tumors, respectively. 


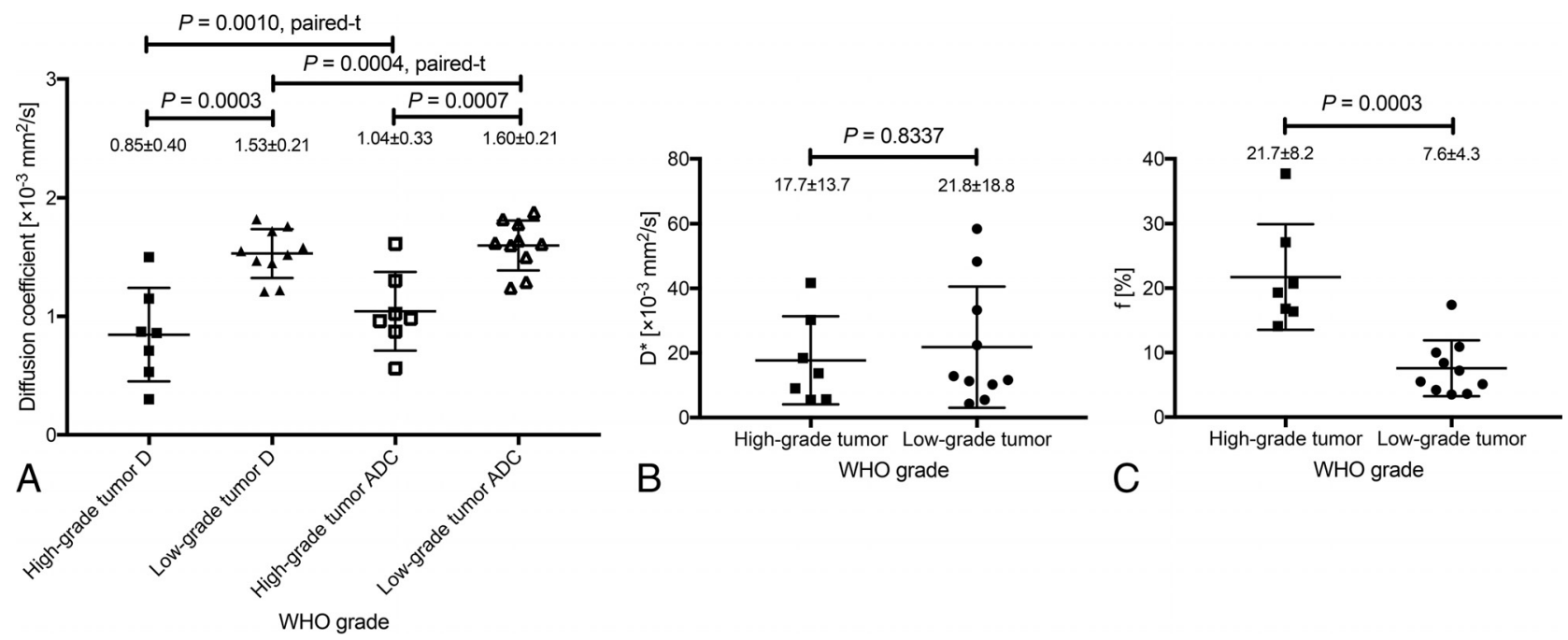

FIG 1. Comparison of the IVIM parameters of high- (WHO grades III and IV) and low-grade (WHO grades I and II) tumors. D and ADC were lower in high-grade than in low-grade tumors $\left(D, 0.85 \pm 0.40\right.$ versus $1.53 \pm 0.21 \times 10^{-3} \mathrm{~mm}^{2} / \mathrm{s}, P=.0003 ; A D C, 1.04 \pm 0.33$ versus $1.60 \pm 0.21 \times 10^{-3}$ $\left.\mathrm{mm}^{2} / \mathrm{s}, P=.0007 ; A\right)$. D was significantly lower than the ADC in high- $(P=.0010)$ and low-grade $(P=.0004 ; A)$ tumors. $D^{*}$ showed wide variability and no significant differences between the high- and low-grade groups $(P=.8337 ; B)$. The $\mathrm{f}$ was higher in high- than in low-grade tumors $(21.7 \pm$ $8.2 \%$ versus $7.6 \pm 4.3 \%, P=.0003 ; C)$.

Table 2: Comparison of parameters between high- and low-grade tumors ${ }^{\mathrm{a}}$

\begin{tabular}{lllr}
\multicolumn{1}{c}{ Parameters } & \multicolumn{1}{c}{ High-Grade Tumor } & \multicolumn{1}{c}{ Low-Grade Tumor } & $P$ Value \\
\hline $\mathrm{D}\left(\times 10^{-3} \mathrm{~mm}^{2} / \mathrm{s}\right)$ & $0.30-1.50,0.86,0.85 \pm 0.40$ & $1.21-1.82,1.54,1.53 \pm 0.21$ & $.0003^{\mathrm{b}}$ \\
$\mathrm{ADC}\left(\times 10^{-3} \mathrm{~mm}^{2} / \mathrm{s}\right)$ & $0.56-1.61,0.98,1.04 \pm 0.33$ & $1.24-1.88,1.62,1.60 \pm 0.21$ & $.0007^{\mathrm{b}}$ \\
$\mathrm{D}^{*}\left(\times 10^{-3} \mathrm{~mm}^{2} / \mathrm{s}\right)$ & $5.5-41.7,13.7,17.7 \pm 13.7$ & $4.3-58.4,12.8,21.8 \pm 18.8$ & $.8337^{\mathrm{c}}$ \\
$\mathrm{f}(\%)$ & $14.1-37.7,19.3,21.7 \pm 8.2$ & $3.5-17.4,6.4,7.6 \pm 4.3$ & $.0003^{\mathrm{b}}$ \\
MVD (\%) & $3.1-34.7,10.2,12.3 \pm 10.5$ & $1.1-13.4,3.6,4.3 \pm 3.6$ & $.0431^{\mathrm{c}}$ \\
MIB-1 (\%) & $15.6-72.6,50.0,42.7 \pm 22.8$ & $0.1-8.0,3.4,3.5 \pm 2.8$ & $<.0001^{\mathrm{b}}$ \\
\hline
\end{tabular}

${ }^{a}$ Data are expressed as range, median, mean.

b Unpaired test.

cMann-Whitney $U$ test.

Table 3: Diagnostic performance of parameters in differentiating high- and low-grade tumors

\begin{tabular}{lcccc}
\hline \multicolumn{1}{c}{ Parameters } & Cutoff Value & Sensitivity (\%) & Specificity (\%) & AUC \\
\hline $\mathrm{D}\left(\times 10^{-3} \mathrm{~mm}^{2} / \mathrm{s}\right)$ & $\leq 1.15$ & 85.7 & 85.7 & 0.943 \\
$D^{*}\left(\times 10^{-3} \mathrm{~mm}^{2} / \mathrm{s}\right)$ & $>9.0$ & 42.9 & 22.9 & 0.536 \\
$\mathrm{f}(\%)$ & $>14.1$ & 100 & 90.0 & 0.957 \\
$\mathrm{ADC}\left(\times 10^{-3} \mathrm{~mm}^{2} / \mathrm{s}\right)$ & $\leq 1.02$ & 71.4 & 71.4 & 0.907 \\
$D+\mathrm{f}$ & $\leq 1.50,>16.4$ & 100 & 90.0 & 0.986 \\
\hline
\end{tabular}

Note:-AUC indicates area under the curve.

\section{DISCUSSION}

We found significant correlations between the histology and IVIM parameters of different pediatric intracranial tumors. These results suggest that IVIM imaging reflects cell density and vascularity across different types of pediatric brain tumors. Our findings are consistent with those of previous studies showing a significant correlation between histology and IVIM parameters in animal models ${ }^{16,17}$ and human patients. ${ }^{6,12,16,17}$ To our knowledge, no previous study has evaluated the correlation between the IVIM parameters and the histology of intracranial tumors in children. Furthermore, we demonstrated that both the diffusion and perfusion parameters measured on IVIM imaging are useful for grading intracranial neuroectodermal tumors in pediatric patients.

Both of the diffusion parameters (ie, D and ADC) demonstrated good sensitivity and specificity for grading pediatric intra- cranial tumors. Diffusion parameters reflect the movement of water molecules, which is hindered in some pathologic states (eg, intracellular edema). The ADC has been reported to have high sensitivity in detecting cell density. ${ }^{23-25}$ The increased number of cell membranes in tumors leads to narrowing of the interstitial space as well as the reduction in the size of the intracellular space, which results in decreased water movement. Thus, the ADC has been used to evaluate cell density in many types of cancer. In previous studies, the ADC was typically calculated using $2 \mathrm{~b}$-values (ie, 0 and $\left.1000 \mathrm{~s} / \mathrm{mm}^{2}\right) .^{3,4,24}$ However, in the present study, the $\mathrm{D}$ values were significantly lower than the ADC values in both tumor groups. Moreover, there was a $23.3 \%$ difference between the $\mathrm{D}$ and ADC in high-grade tumors. This difference most likely reflects the increased perfusion fraction of malignant tumors. ${ }^{12}$ With small perfusion fractions, the following relationship applies: $(A D C-D) \sim f / b$. Applying the ADC and $D$ values of low- and high-grade tumors found in this study to this relationship (ie, ADC - D) produces values of $1.9 \times 10^{-4} \mathrm{~mm}^{2} / \mathrm{s}$ (high-grade tumors) and $0.6 \times 10^{-4} \mathrm{~mm}^{2} / \mathrm{s}$ (low-grade tumors) These values are very close to the $\mathrm{f} / \mathrm{b}\left(b=1000 \mathrm{~s} / \mathrm{mm}^{2}\right)$ values of $2.2 \times 10^{-4} \mathrm{~mm}^{2} / \mathrm{s}$ and $0.8 \times 10^{-4} \mathrm{~mm}^{2} / \mathrm{s}$ for high- and low-grade tumors, respectively.

These findings provide strong support for the results and validate the method. Furthermore, the correlation value for the MIB-1 proliferation index and D was higher than for the MIB-1 proliferation index and ADC. This result indicates that D more precisely reflects the tumor cell density than the ADC. We also demonstrated that $\mathrm{D}$ had better diagnostic performance than the 

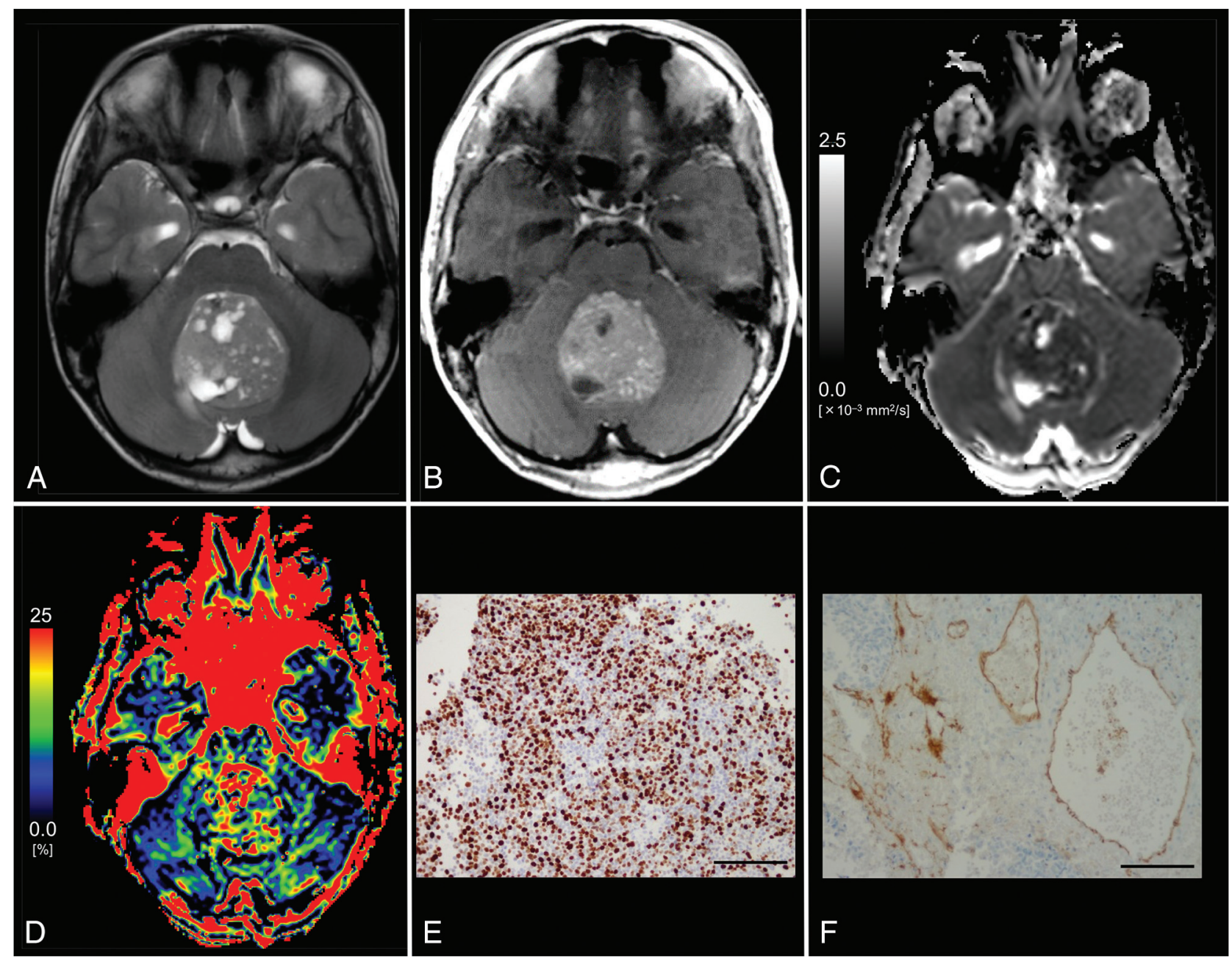

FIG 2. Images from an 11-year-old boy with histologically defined classic medulloblastoma (WHO grade IV). A, T2WI shows a heterogeneous, hyperintense mass in the vermis. $B$, Contrast-enhanced TIWI shows heterogeneous enhancement of the tumor. $C$, The $D$ map shows the low $D$ value $\left(0.53 \times 10^{-3} \mathrm{~mm}^{2} / \mathrm{s}\right)$ of the lesion, which is lower than the cutoff value $\left(\leq 1.15 \times 10^{-3} \mathrm{~mm}^{2} / \mathrm{s}\right.$; Table 3$)$. D, The $\mathrm{f}$ map shows the $f$ value $(27.1 \%)$ of the lesion, which is higher than the cutoff value (>14.1\%; Table 3). E, MIB-1 staining reveals a high MIB-1 index (72.6\%). F, Immunohistochemical staining for anti-CD31 shows a high MVD (10.2\%). Bar $=100 \mu \mathrm{m}$.

$\mathrm{ADC}$ for differentiating high- and low-grade tumors. In this study, the ADC derived using a pair of b-values had acceptable diagnostic performance for grading; however, the diagnostic performance accuracy using $\mathrm{D}$ was an improvement over the conventional ADC.

Of the perfusion parameters, $f$ may reflect tumor vascularity. In general, malignant tumors, in particular gliomas, are hypervascular. Hypervascularity is another important consideration for the histopathologic diagnosis of tumors because malignancy progression is accompanied by neoangiogenesis. ${ }^{26}$ We demonstrated that the MVD reflects neoangiogenesis progression and its measured values correlated closely with those of $f$. The $f$ was higher in high-grade than in low-grade tumors, a finding consistent with previous IVIM studies in adults. ${ }^{12,13}$ Our study may be the first to demonstrate the value of IVIM imaging in pediatric patients with intracranial neuroectodermal tumors. Many researchers have used arterial spin-labeling to grade pediatric tumors because this method can evaluate cerebral blood flow without a contrast agent. Similar to arterial spin-labeling, $\mathrm{f}$ can also be measured without contrast agent.
This noninvasive feature is useful for children. However, $\mathrm{D}^{*}$ was not helpful for tumor grading. This finding has been previously reported in adult IVIM studies. ${ }^{12,19}$ Moreover, other studies have suggested that $\mathrm{D}^{*}$ is poorly reproducible ${ }^{27,28}$ and could be substantially affected by cardiac motion. ${ }^{29}$ The cardiac-gating technique may improve $\mathrm{D}^{\star}$ assessment in tumors. ${ }^{30}$

The combined $\mathrm{D}$ and $\mathrm{f}$ had the best diagnostic performance of all parameters investigated in our study. Combining $D$ and $f$ increased the area under the curve compared with each parameter alone. In combination, these 2 parameters can be used to evaluate different pathologic features of intracranial tumors. For example, some infantile tumors have high vascularity and low cell density (ie, hemangioblastoma or choroid plexus papilloma). IVIM imaging can simultaneously evaluate both diffusion and perfusion parameters in the same anatomic space; this feature improves diagnostic accuracy in such tumors. However, it is still difficult to differentiate high-grade tumors, such as medulloblastoma and atypical teratoid/rhabdoid tumor, which have the same pattern of high vascularity and cell density. In 

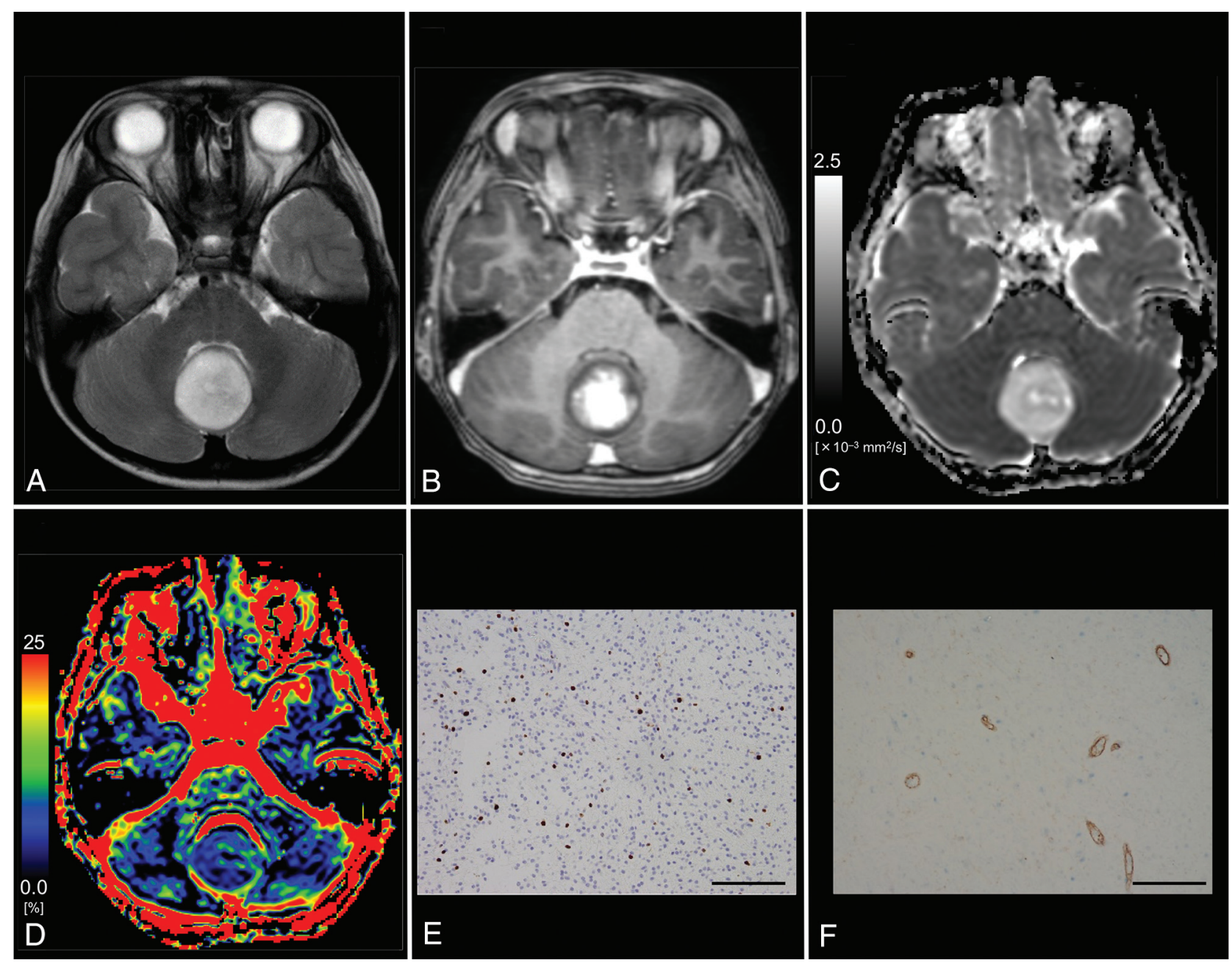

FIG 3. Images from a 6-year-old boy with pilocytic astrocytoma (WHO grade I). $A, T 2 \mathrm{WI}$ shows a homogeneous, hyperintense mass in the vermis. $B$, Contrast-enhanced TIWI shows mild, heterogeneous enhancement of the tumor. $C$, The $D$ map shows the high $\mathrm{D}$ value $\left(1.72 \times 10^{-3} \mathrm{~mm}^{2} / \mathrm{s}\right)$ of the lesion, which is higher than the cutoff value $\left(\leq 1.15 \times 10^{-3} \mathrm{~mm}^{2} / \mathrm{s}\right.$; Table 3$)$. $D$, The $\mathrm{f}$ map shows the low $\mathrm{f}$ value $(4.2 \%)$ of the lesion, which is lower than the cutoff value (>14.1\%; Table 3). E, MIB-1 staining reveals a low MIB-1 index (6.0\%). $F$, Immunohistochemical staining for anti-CD3 reveals a low MVD (3.2\%). Bar $=100 \mu \mathrm{m}$.

such cases, basic information (ie, tumor location and patient age) is essential.

A strength of this study was that histologic diagnoses were available for all patients. However, this study also had some limitations. First, the sample size was very small, especially for patients with grade II glioma $(n=1)$. Second, the ROI analyses were subjective, which may have introduced selection bias. However, in clinical practice, ROI analysis is often used for diagnosis. ${ }^{6,12,19}$ Automatic tumor segmentation, which involves computeraided segmentation and histogram analysis, could help address this issue. Third, the IVIM model used in this study does not account for non-Gaussian diffusion effects, which may lead to the overestimation of f. ${ }^{15}$ Non-Gaussian fitting may improve the accuracy of $f$, especially with very high b-values. Fourth, we used only 3 perpendicular directions for diffusion encoding. In anisotropic tissues, (eg, white matter), anisotropic analysis via the diffusion tensor imaging method requires the use of at least 6 directions; however, in clinical practice, DWI averaged over 3 directions is often used during the diagnostic process.

\section{CONCLUSIONS}

IVIM imaging reflected histology, which suggests that it may be a helpful noninvasive diagnostic method for intracranial neuroectodermal tumor grading in children.

Disclosures: Kazufumi Kikuchi—RELATED: Grant:Japan Society for the Promotion of Science KAKENHI, Comments: grant No. JP 18H06164.

\section{REFERENCES}

1. Pollack IF. Brain tumors in children. $N$ Engl J Med 1994;331: 1500-07 CrossRef Medline

2. Gajjar A, Packer RJ, Foreman NK, et al. Children's Oncology Group's 2013 blueprint for research: central nervous system tumors. Pediatr Blood Cancer 2013;60:1022-26 CrossRef Medline

3. Gauvain KM, McKinstry RC, Mukherjee P, et al. Evaluating pediatric brain tumor cellularity with diffusion-tensor imaging. AJR Am J Roentgenol 2001;177:449-54 CrossRef Medline

4. Tzika AA, Zarifi MK, Goumnerova L, et al. Neuroimaging in pediatric brain tumors: Gd-DTPA-enhanced, hemodynamic, and diffusion MR imaging compared with MR spectroscopic imaging. AJNR Am J Neuroradiol 2002;23:322-33 Medline

5. Yeom KW, Mitchell LA, Lober RM, et al. Arterial spin-labeled per-

AJNR Am J Neuroradiol 40:878-84 May 2019 www.ajnr.org

883 
fusion of pediatric brain tumors. AJNR Am J Neuroradiol 2014;35: 395-401 CrossRef Medline

6. Kikuchi K, Hiwatashi A, Togao O, et al. Correlation between arterial spin-labeling perfusion and histopathological vascular density of pediatric intracranial tumors. J Neurooncol 2017;135:561-69 CrossRef Medline

7. Chang YW, Yoon HK, Shin HJ, et al. MR imaging of glioblastoma in children: usefulness of diffusion/perfusion-weighted MRI and MR spectroscopy. Pediatr Radiol 2003;33:836-42 CrossRef Medline

8. Huisman TA, Sorensen AG. Perfusion-weighted magnetic resonance imaging of the brain: techniques and application in children. Eur Radiol 2004;14:59-72 Medline

9. Sugahara T, Korogi Y, Kochi M, et al. Usefulness of diffusionweighted MRI with echo-planar technique in the evaluation of cellularity in gliomas. J Magn Reson Imaging 1999;9:53-60 CrossRef Medline

10. Sugahara T, Korogi $Y$, Kochi M, et al. Correlation of MR imagingdetermined cerebral blood volume maps with histologic and angiographic determination of vascularity of gliomas. AJR Am J Roentgenol 1998;171:1479-86 CrossRef Medline

11. Le Bihan D, Breton E, Lallemand D, et al. Separation of diffusion and perfusion in intravoxel incoherent motion MR imaging. Radiology 1988;168:497-505 CrossRef Medline

12. Togao O, Hiwatashi A, Yamashita K, et al. Differentiation of highgrade and low-grade diffuse gliomas by intravoxel incoherent motion MR imaging. Neuro Oncol 2016;18:132-41 CrossRef Medline

13. Sumi M, Nakamura T. Head and neck tumors: assessment of perfusion-related parameters and diffusion coefficients based on the intravoxel incoherent motion model. AJNR Am J Neuroradiol 2013;34: 410-16 CrossRef Medline

14. Surov A, Meyer HJ, Höhn AK, et al. Correlations between intravoxel incoherent motion (IVIM) parameters and histological findings in rectal cancer: preliminary results. Oncotarget 2017;8:21974-83 CrossRef Medline

15. Iima M, Yano K, Kataoka M, et al. Quantitative non-Gaussian diffusion and intravoxel incoherent motion magnetic resonance imaging: differentiation of malignant and benign breast lesions. Invest Radiol 2015;50:205-11 CrossRef Medline

16. Iima M, Reynaud $\mathrm{O}$, Tsurugizawa $\mathrm{T}$, et al. Characterization of glioma microcirculation and tissue features using intravoxel incoherent motion magnetic resonance imaging in a rat brain model. Invest Radiol 2014;49:485-90 CrossRef Medline

17. Lee HJ, Rha SY, Chung YE, et al. Tumor perfusion-related parameter of diffusion-weighted magnetic resonance imaging: correlation with histological microvessel density. Magn Reson Med 2014;71: 1554-58 CrossRef Medline
18. Louis D, Ohgaki H, Wiestler O, et al. WHO Classification of Tumours of the Central Nervous System, Revised. Lyon: International Agency for Research on Cancer; 2016

19. Yamashita K, Hiwatashi A, Togao O, et al. Diagnostic utility of intravoxel incoherent motion MR imaging in differentiating primary central nervous system lymphoma from glioblastoma multiforme. J Magn Reson Imaging 2016;44:1256-61 CrossRef Medline

20. Mikayama R, Yabuuchi H, Sonoda S, et al. Comparison of intravoxel incoherent motion diffusion-weighted imaging between turbo spin-echo and echo-planar imaging of the head and neck. Eur Radiol 2018;28;316-24

21. Gerdes J, Lemke H, Baisch H, et al. Cell cycle analysis of a cell proliferation-associated human nuclear antigen defined by the monoclonal antibody Ki-67. J Immunol 1984;133:1710-15 Medline

22. McCormick D, Chong H, Hobbs C, et al. Detection of the Ki-67 antigen in fixed and wax-embedded sections with the monoclonal antibody MIB1. Histopathology 1993;22:355-60 CrossRef Medline

23. Lyng H, Haraldseth O, Rofstad EK. Measurement of cell density and necrotic fraction in human melanoma xenografts by diffusion weighted magnetic resonance imaging. Magn Reson Med 2000;43: 828-36 CrossRef Medline

24. Chen L, Liu M, Bao J, et al. The correlation between apparent diffusion coefficient and tumor cellularity in patients: a meta-analysis. PLoS One 2013;8:e79008 CrossRef Medline

25. Togao O, Doi S, Kuro-o M, et al. Assessment of renal fibrosis with diffusion-weighted MR imaging: study with murine model of unilateral ureteral obstruction. Radiology 2010;255:772-80 CrossRef Medline

26. Winkler F, Kienast $\mathrm{Y}$, Fuhrmann $\mathrm{M}$, et al. Imaging glioma cell invasion in vivo reveals mechanisms of dissemination and peritumoral angiogenesis. Glia 2009;57:1306-15 CrossRef Medline

27. Andreou A, Koh DM, Collins DJ, et al. Measurement reproducibility of perfusion fraction and pseudodiffusion coefficient derived by intravoxel incoherent motion diffusion-weighted MR imaging in normal liver and metastases. Eur Radiol 2013;23:428-34 CrossRef Medline

28. Meeus EM, Novak J, Withey SB, et al. Evaluation of intravoxel incoherent motion fitting methods in low-perfused tissue. J Magn Reson Imaging 2017;45:1325-34 CrossRef Medline

29. Federau C, Hagmann P, Maeder P, et al. Dependence of brain intravoxel incoherent motion perfusion parameters on the cardiac cycle. PLoS One 2013;8:e72856 CrossRef Medline

30. Habib J, Auer DP, Morgan PS. A quantitative analysis of the benefits of cardiac gating in practical diffusion tensor imaging of the brain. Magn Reson Med 2010;63:1098-103 CrossRef Medline 